\title{
Health services policies and case mix - what would you expect (or not) to happen? Selected findings from Romania and Turkey, 2000- 2008
}

\author{
Dana Burduja
}

Address: Center for Health Policies and Services, 32, Hrisovului St., Vila 9, Ap.23, sect.1, Bucharest, 013162, Romania

Email: Dana Burduja - dburduja@gmail.com

from 24th Patient Classification Systems International (PCSI) Working Conference

Lisbon, Portugal. 8-II October 2008

Published: 27 November 2008

BMC Health Services Research 2008, 8(SuppI I):A5 doi:I0.1 I86/1472-6963-8-SI-A5

This abstract is available from: http://www.biomedcentral.com/I472-6963/8/SI/A5

(c) 2008 Burduja; licensee BioMed Central Ltd.

\section{Introduction}

Both Romania and Turkey started the implementation of case-mix systems as a tool to be used for acute inpatient care reimbursement by the public insurance system, in the context of inflationist, non-transparent and non-equitable reimbursements at the time. Romania used the HCFA DRG system for the initial phases (2000-2005), and it is currently using the AR DRG system for full reimbursement of acute inpatient care (2008). Turkey decided to start directly with AR DRG, but only to pilot technical steps (2005-2008), moving to a locally adapted system to be used for reimbursement (after 2009?).

\section{Methods}

The authors' analysis of the legislative and regulatory frameworks of the health services of the two countries identified selected changes in the organization and funding of the health services along the timeline of case-mix systems' development and implementation (20002008). We evaluated these policy changes using mainly direct information from the official decision-making process of the responsible institutions, and compared our findings against literature and international experience. All major changes in the organization or funding of the healthcare systems were evaluated, no matter how casemix systems were used at the time of respective change (piloting, testing technical tools, reimbursement, budget neutral, etc.).

\section{Results}

The results were grouped around four major areas of the health system: 1 . data and MIS; 2 . organization, delivery and reimbursement of different types of care; 3 . hospitals management and performance evaluation; 4 . costing of health services.

Patient level clinical and demographic data and MIS: In Romania, no data was available at the patient level before introducing the case-mix system; however, in Turkey this data was widely available at the hospital level (but with almost no standardization). MIS systems in Romania were almost nonexistent (2000), as opposed to Turkey (2005), with a wide range of MIS, but again lacking any standardization. Presently, standardized data sets are collected in a structured manner and linked directly with payments (Romania, 2008); however, in Turkey almost no formal legal empowerment of the existing pilot standardized tools is in place (2008), apart from the recently published standards of the National Health Data Dictionary (2008). Standardized clinical and cost data are being collected from 40 pilot hospitals in Turkey.

Types of care: Romania took a step-by-step approach in restructuring provision and contracting of different types of care, especially as correspondent payment systems were developed (starting with 2002, as case-mix based reimbursement started). In Turkey, types of care are only standardized as primary and hospital care, as organization and delivery of ambulatory care (separately or within hos- 
pitals) is strongly biased by the fee-for-service payment scheme (2008). Minor changes are envisaged, to allow contracting for health services by 2009 .

Hospital management and performance evaluation: Romania used available (clinical) data initially as support for decision making at the hospital level; standard reports and analyses were provided in the early years of the casemix implementation to hospitals (2000-2005); the same reports were promoted at the central level (aggregated) and some of them are now in use (2008) as performance evaluation tools for hospital management teams. Turkey has longer and better experience in clinical data collection and utilization of the MIS systems (even though not standardized), and internal hospital reports are commonly used, both clinical and financial/cost data. Unfortunately, apart from official international organizations reporting, no major use of this data is being made at the central level.

\section{Conclusion}

Some policy decisions were known long ago as prerequisites for starting a basic case-mix system (coding and collection of clinical data), and they were applied accordingly to Turkey and Romania.

Other policy decisions in the two countries were purely and consistently driven by case mix, like type of care definition or standardization, hospital performance evaluation, etc. Some of them are the result of the local approach in using and implementing case mix for payments (for example, in Romania, day-stay care is considered purely ambulatory care, and in Turkey, inpatient care).

The main paradox and difference remains the relationship between costing and case-mix payment for inpatient acute care, which is quite unusual when compared with other countries: Romania has (almost) no costing data available and uses the system for full reimbursement; however, Turkey has good costing data available (together with the other case-mix tools), and no reimbursement policy has been yet legislated (even though it has been considered).

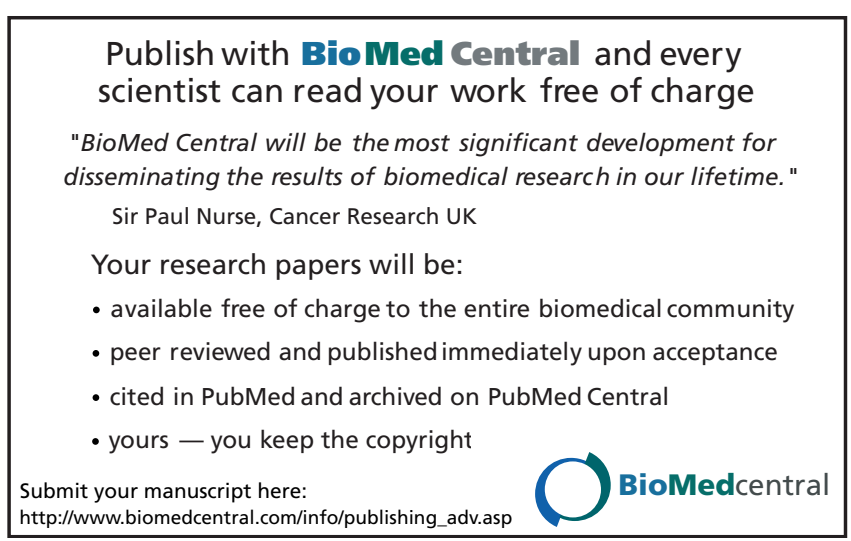

Page 2 of 2

(page number not for citation purposes) 